\title{
Optimizing Non-linear Granular Layer Coefficients of a Flexible Pavement for Mechanistic-Empirical Method
}

\author{
Murat BOSTANCIOĞLU ${ }^{1}$
}

\begin{abstract}
In recent years, mechanistic-empirical (M-E) design methods are preferred in the design of flexible pavements instead of empirical methods using equations based on the road performance tests. However, the calibration of transfer equations that convert mechanical responses to pavement life and the definition of layer materials used in M-E methods have great importance for M-E methods.

In this study, mechanical analyses of a cross-section designed with the AASHTO-93 method were performed, and service life values were calculated with different empirical transfer equations. The obtained M-E design results were compared with the results calculated with the AASHTO-93 method, and transfer equations compatible with the AASHTO-93 method were determined. Among the transfer equations examined, it was found that the rutting equation of the Asphalt Institute gave the most consistent results with the AASHTO-93 method. In the mechanical analysis of the selected cross-section, granular base and sub-base layers were defined as non-linear elastic reflecting the actual in-situ conditions. K- $\Theta$ model was preferred for non-linear elastic layer definition, and $\mathrm{K}_{1}$ and $\mathrm{K}_{2}$ parameters of this model were optimized.
\end{abstract}

Keywords: Mechanistic-empirical design, AASHTO-93 method, non-linear layer coefficients, pavement life, rutting, fatigue.

\section{INTRODUCTION}

Flexible pavements consist of granular base and sub-base layers and a bituminous surface layer built on the subgrade to ensure the comfort and safety of vehicles and to resist the stresses caused by traffic loads and environmental conditions. The main purpose of pavement design is to determine the appropriate thickness of the layers subject to traffic loads and environmental effects. The methods used in flexible pavement design can be examined in five different categories as empirical methods, limiting shear failure method, limiting deflection method, regression method, and mechanistic-empirical (M-E) method [1-4].

\footnotetext{
Note:

- This paper was received on October 23, 2019 and accepted for publication by the Editorial Board on May 23, 2020.

- Discussions on this paper will be accepted by January 31, 2022.

- https://dx.doi.org/10.18400/tekderg.637166

1 Sivas Cumhuriyet University, Department of Civil Engineering, Sivas, Turkey bostancioglu@cumhuriyet.edu.tr - https://orcid.org/0000-0001-6820-2213
} 
AASHTO-93 method, which uses regression equations related to road performance tests, is preferred by Turkey General Directorate of Highways for the design of flexible pavements $[1,5,6]$. The AASHTO pavement design guide was first published in 1961 and was revised in 1972, 1981, 1986 and 1993 with the theoretical support added to the knowledge obtained from the road test. The equations used in the AASHTO method were obtained from the Ottowa Illinois road tests and used certain climatic conditions, specific layer materials, and a certain subgrade. The average annual rainfall in the region where the test track is $864 \mathrm{~mm}$ and the frost depth is $711 \mathrm{~mm}$. The subgrade has inadequate drainage and the California bearing ratio (CBR) ranges from $2 \%$ to $4 \%$ [1-3]. In the AASHTO method, the number of load repetitions is a very important point to take into consideration and loads of all types of vehicles in traffic are converted to the equivalent axle load of 8.2 tonnes $\left(\mathrm{T}_{8.2}\right)$ [5]. The present serviceability index (PSI) is located in the design equation based on pavement roughness and distress conditions (fatigue, cracking and patching) [1,4,5]. The low traffic volumes, dated vehicle characteristics, short test times and limited material and climatic properties used in AASHTO road tests have led to questioning the usability of the method. Similar to the AASHTO method, these limitations observed in all empirical methods increased interest in M-E methods [2,4].

Unlike empirical procedures, the M-E design method is more adaptable to changing loading, material, construction, and environmental conditions. In the M-E method, the design is performed with different transfer equations for all types of distress modes (rutting, fatigue cracking, etc.) $[2,7,8]$.

The mechanical part of the M-E design methods is based on basic material mechanics, and stress, strain and displacement values (outputs) are calculated at any depth of the crosssection depending on traffic loads, environmental loads and layer characteristics (inputs) on the road $[1,9]$. In the empirical part, these mechanical responses are converted to service life by transfer equations (pavement life estimation models) [8].

Burmister's layered theory $[1,10]$ is one of the most practical methods for mechanical analysis of flexible pavements. In this theory, the layers are defined as linear elastic with the modulus of elasticity (E) and Poisson's ratio (v). The Burmister theory can also be used in mechanical analysis of multilayered systems containing viscoelastic and nonlinear layers with some modifications [1].

Material characterization is a crucial step for mechanical analysis. The mechanical responses of the pavement can be estimated by the theory of elasticity where stresses from external loads are relatively low. However, in real conditions, heterogeneous pavement layers can behave more differently than ideal. Where the bituminous surface layer is thick, the elastic theory applies, whereas in relatively thin surface layers the mechanical response is significantly affected by the nonlinear behavior of the granular layers and the subgrade [11].

The modulus of elasticity calculated based on the recoverable strain of material under repetitive loads is defined as the resilience module $\left(\mathrm{M}_{R}\right)$ of the material and is the ratio of deviator stress to recoverable strain in the three-axial test [1]. $M_{R}$ is the most important mechanical parameter used to characterize the subgrade, sub-base and base layers under repeated loads as the materials used in the layers exhibit permanent deformation under repeated loads $[12,13]$. 
In the literature, many studies are showing the variation of flexible pavement performances depending on the $\mathrm{M}_{\mathrm{R}}$ values of unbound layers and their characterization;

Shahji (2006) [14] and Masad and Little (2004) [15] stated in their studies that the total rutting on the pavement decreased as $M_{R}$ increased. Cerni et al. (2012) [16] and Masad and Little (2004) [15] revealed that load-related cracks occur easily due to the decreasing $M_{R}$ value. In their study, which presented the relationship between $M_{R}$ and thermal cracks, Şahin et al. (2013) [17] reported that thermal cracks accelerated due to $M_{R}$ decrease. Masad and Little (2004) [15] reported that the International Roughness Index (IRI) value decreased due to the increase in the base layer $M_{R}$.

Numerous models have been proposed in the literature for modeling granular layers and estimating $M_{R}$ values of unbound granular layers which are highly effective on flexible pavement performance as mentioned above. $\mathrm{M}_{\mathrm{R}}$ prediction models are categorized in the literature as follows [13, 18-23];

(1) Empirical regression models

(2) Nonlinear stress-dependent models

(3) Moisture-sensitive models

(4) Moisture-sensitive and stress-dependent models

(5) Stress-dependent and cross-anisotropic models

(6) Moisture-sensitive, stress-dependent, and cross-anisotropic model

(7) Regression models for stress-dependent model coefficients

(8) Regression models for moisture-sensitive and stress-dependent model coefficients

In the studies conducted in the literature, the importance of defining stress-dependency and anisotropic material in the determination of $\mathrm{M}_{\mathrm{R}}$ values of unbound layers was emphasized. In the study that investigated the effect of the definition of unbound layers on mechanical analysis, Masad et al. (2005) [24] showed that permanent deformation values increase significantly when non-linear and anisotropic properties are used. Adu-Osei et al. (2001) [25] reported that fatigue cracking life is reduced if cross-anisotropy is used in the base layer. Masad and Little (2004) [15] reported that total rutting and cracking, which led the IRI change, were affected by cross-anisotropy. Tutumluer (1995) [26] denoted that the $M_{R}$ and Poisson's ratio values of unbound layers are direction-dependent. Hence, cross-anisotropic elastic modeling is a better method to estimate the behavior of these layers than the isotropic elastic model.

In the studies carried out to determine the $\mathrm{M}_{\mathrm{R}}$ values of the unbound layers depending on the moisture content [27-31], it was stated that the moisture content is the main parameter especially in the prediction of the subgrade's $M_{R}$ value, and the high degree of moisture content change decreases the $\mathrm{M}_{\mathrm{R}}$. In the study investigating the effect of moisture content in the base layer on tensile strains under the surface layer, Luo et al. (2017) [23] found that tensile strains increased due to the increase in the moisture content of the base layer.

For the K- $\Theta$, Uzan-Witczak and Lade-Nelson models are among the most well-known models for non-linear granular layer characterization. Among these models, the Uzan- 
Witczak model provides the lowest surface displacement and horizontal strain under the surface layer at the same loading conditions, while the Lade-Nelson model gives the highest values. K- $\Theta$ model calculated the responses between the results of these two methods [32].

The K-Ө model (Equation 1), proposed by Seed et al. [19] where $M_{R}$ is a function of the sum of the principal stresses, is frequently used in $\mathrm{M}_{\mathrm{R}}$ estimation and is used in the definition of the non-linear elastic granular layer in the current study $[33,34]$.

$M_{R}=K_{1} \theta^{K_{2}}$

In Equation 1, $\Theta$ is the sum of the principal stresses in the dynamic three-axial test, and $\mathrm{K}_{1}$ and $\mathrm{K}_{2}$ are the regression constants obtained from the experimental data of the material. Because the model is simple and useful, there are many studies in which model parameters are determined for different soil types [35-40].

There are many studies for the use of the M-E method in pavement design, but it is not widely used because of limitations on the calibration of empirical transfer functions [2]. In this study, the empirical transfer equations used in the M-E design method were found to be compatible with the AASHTO-93 for a selected pavement cross-section. Thus, the mechanical responses and pavement life of a cross-section designed with the AASHTO-93 can be determined by the M-E method under different loading, material, and environmental conditions and compared with the AASHTO-93. The present study is original in comparing the transfer equations of the M-E method with an empirical one. Furthermore, the study aims to optimize the nonlinear granular layer coefficients $\left(\mathrm{K}_{1}\right.$ and $\left.\mathrm{K}_{2}\right)$ used in the M-E method, which is highly effective on the mechanical responses and proposed in a wide range in the literature.

As a result of optimizing the layer coefficients, the material types and moisture contents of the unbound layers used in the M-E method will be more specifically defined. Thus, the error rate for defining materials will be minimized in the calculation of cross-section responses.

\section{MATERIAL AND METHODS}

A conventional flexible pavement cross-section (Figure 1) was selected in the study, and layer thicknesses were determined following the studies in the literature [31,33,41-44]. The mechanical and physical properties of the layers are defined by the Highway Flexible Pavement Design Guide [5] and the maximum number of standard axle loads that the crosssection could be passed, over its economic life was determined by the AASHTO-93 method (Equation 2) [1,5].

$\log \left(T_{8.2}\right)=Z_{R} x S_{0}+9.36 x \log (S N+1)-0.20+\frac{\log \left(\frac{\Delta P S I}{4.2-1.5}\right)}{0.40+\frac{1094}{(S N+1)^{5.19}}}+2.32 x \log \left(M_{R}\right)-8.07$

Where,

$\mathrm{Z}_{\mathrm{R}}$ : The standard normal deviation of reliability $(\mathrm{R})$ is recommended as -1.645 for highways, -1.037 for state roads, and -0.524 for provincial roads. 
$\mathrm{S}_{0}$ : The combined total standard deviation of traffic and performance estimation is suggested between $0.40-0.50$ and is used as 0.45 .

$\triangle$ PSI: The decrease in serviceability index $\left(\mathrm{P}_{0}-\mathrm{P}_{\mathrm{t}}\right) . \mathrm{P}_{0}$ is the initial serviceability index between 4.2-4.5 when the road is first opened to traffic. In this study, this value was used as 4.2. $\mathrm{P}_{\mathrm{t}}$ is the terminal serviceability index and 2.5 for highways and state roads, 2.0 for provincial roads.

$\mathrm{M}_{\mathrm{R}}$ : Resilient modulus (psi)

$\mathrm{SN}$ : Structural number (inches), is calculated by Equation 3 based on the thicknesses (Di, Dj) of the layers, the layer coefficients (ai, aj) and the drainage coefficients (mj) of the granular layers.
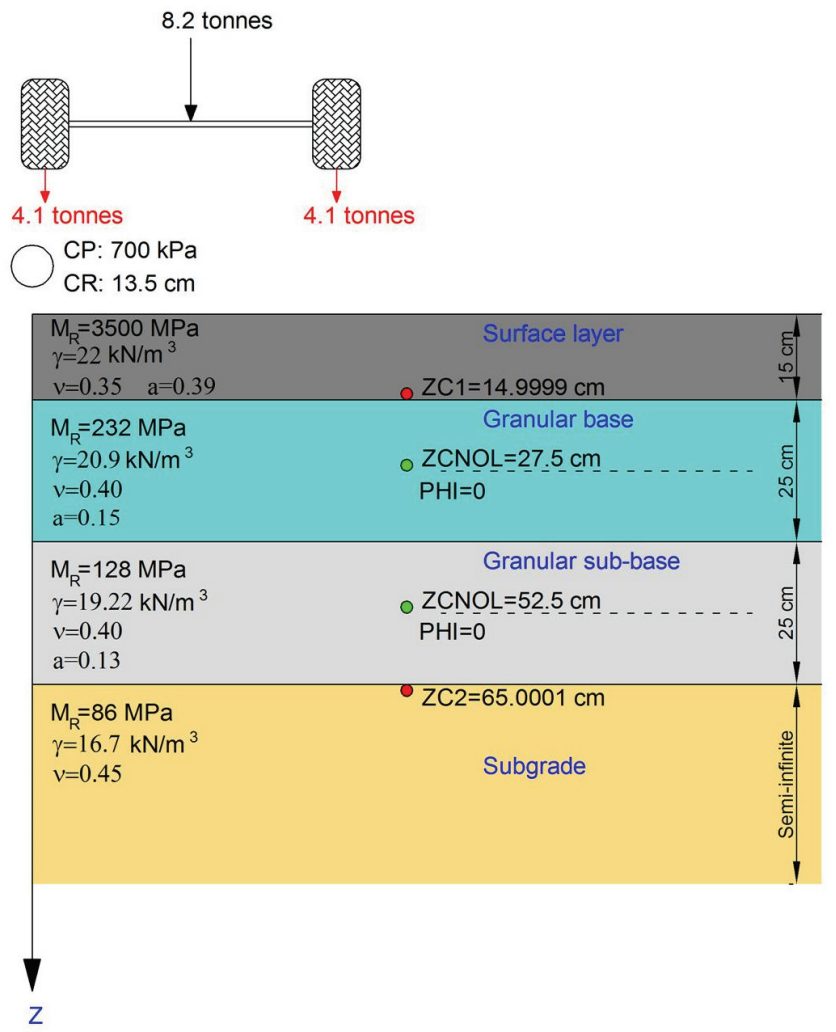

Figure 1 - Model geometry

$S N=\sum_{i=1}^{k} a_{i} D_{i}+\sum_{j=1}^{n} a_{j} D_{j} m_{j}$

Where,

$\mathrm{k}$ denotes the number of hot mix asphalt (HMA) layers and $\mathrm{n}$ denotes the number of granular layers. Granular layer drainage coefficients were taken as 1.0. The layer coefficients to be 
used in the AASHTO-93 method were obtained with the help of Figure 2, Equations 4 and 5 respectively for surface, base and sub-base layers depending on the layer resilient modulus values and are given in Figure 1 [1].

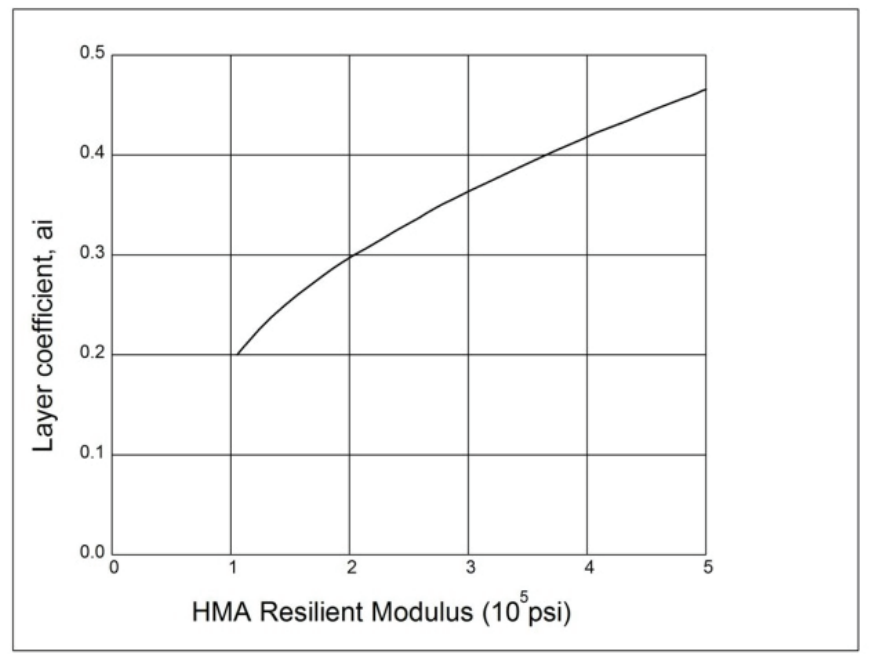

Figure 2 - Layer coefficients due to HMA resilient modulus [1]

$a_{\text {base }}=0.249 x \log \left(M_{R_{\text {base }}}\right)-0.977$

$a_{\text {sub-base }}=0.227 x \log \left(M_{R_{\text {sub-base }}}\right)-0.839$

In Equations 4 and 5, the $\mathrm{M}_{\mathrm{R} \text { base }}$ and $\mathrm{M}_{\mathrm{R} \text { sub-base }}$ indicate the resilient modulus (psi) of the base and sub-base layers.

In the M-E design method, the mechanical responses (displacement, stress, and strain) should be converted to a parameter that reflects the pavement performance (rutting, fatigue, cracking, etc.). The most commonly used mechanical parameters for this purpose are the horizontal strain $\left(\varepsilon_{\mathrm{r}}\right)$ under the surface layer $\left(\mathrm{ZC} 1\right.$ in Figure 1) and the vertical strain $\left(\varepsilon_{\mathrm{v}}\right)$ on the subgrade (ZC2 in Figure 1). If horizontal strains are excessive, cracks occur on the surface, and this is called fatigue criterion. If vertical strains are excessive, deformations occur on the pavement, and this is called the rutting criterion $[8,45,46]$. In the literature, there are various models for fatigue and rutting criteria, and the general forms of these models are given in Equations 6 and 7, and the coefficients (f1-f5) used in the equations are given in Table $1[8,47]$.

$N_{f}=f 1 \varepsilon_{r}^{-f 2} M_{R_{\text {surface }}}{ }^{-f 3}$

$N_{r}=f 4\left(\varepsilon_{v}\right)^{-f 5}$ 
Where $\mathrm{N}_{\mathrm{f}}$ is the number of load repetitions required for fatigue, $\mathrm{N}_{\mathrm{r}}$ is the number of load repetitions required for rutting distress, $M_{R}$ surface is the resilient modulus (psi) of the surface layer.

Table 1 - Distress model coefficients for different agencies [8,47]

\begin{tabular}{|c|c|c|c|c|c|c|c|c|}
\hline & 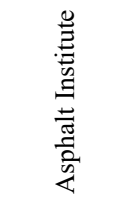 & 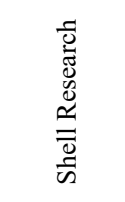 & 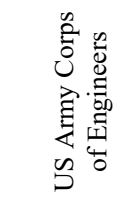 & 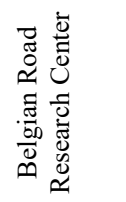 & 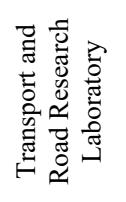 & 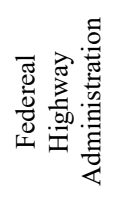 & 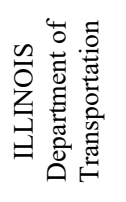 & 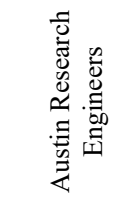 \\
\hline f1 & 0.0795 & 0.0685 & 497.156 & $4.92 \mathrm{E}-14$ & $1.66 \mathrm{E}-10$ & 0.1001 & $5.00 \mathrm{E}-06$ & $4.88 \mathrm{E}-01$ \\
\hline $\mathrm{f} 2$ & 3.291 & 5.671 & 5 & 4.76 & 4.32 & 3.565 & 3 & 3.0312 \\
\hline f3 & 0.854 & 2.363 & 2.66 & 0 & 0 & 1.474 & 0 & 0.6529 \\
\hline $\mathrm{f} 4$ & $1.37 \mathrm{E}-09$ & $6.15 \mathrm{E}-07$ & $1.81 \mathrm{E}-15$ & $3.05 \mathrm{E}-09$ & $1.13 \mathrm{E}-06$ & --- & --- & --- \\
\hline f5 & 4.477 & 4 & 6.527 & 4.35 & 3.75 & --- & --- & --- \\
\hline
\end{tabular}

To determine which of the empirical transfer equations used in the M-E design method yielding consistent results with the AASHTO-93 method, mechanical analysis of the crosssection was performed, and the strain values were obtained under the surface layer and on the subgrade. The obtained values were converted to pavement life and compared with the $\mathrm{T}_{8.2}$ values of the AASHTO-93 method, and the transfer equations compatible with the AASHTO-93 method were obtained. KENLAYER software was used for mechanical analysis, which can be used successfully in the determination of displacement, stress and strain values of multilayered systems defined as linear elastic, non-linear elastic and viscoelastic under single, dual, dual tandem and dual tridem loading $[1,7,48,49]$.

The layer thicknesses of the section are defined on the z-axis, and layer parameters $\left(M_{R}\right.$ and v) and unit weights of the layers are given in Figure 1. The wheel load is defined as 4.1 tonnes on the single wheel following the AASHTO-93 method. The contact pressure (CP) of the wheel was selected as $700 \mathrm{kPa}$ [50], and the circular wheel contact radius (CR) that would provide this internal pressure was determined as $13.5 \mathrm{~cm}$. During the mechanical analysis, the contact surfaces between the layers were selected as bonded.

Table 2 - Non-linear layer coefficients

\begin{tabular}{lccccc}
\hline Layer & $\mathrm{K}_{0}$ & $\mathrm{~K}_{1}(\mathrm{kPa})$ & $\mathrm{K}_{2}$ & $\mathrm{PHI}$ & ZCNOL $(\mathrm{cm})$ \\
\hline Base & 0.67 & Variable & Variable & 0 & 27.5 \\
Sub-base & 0.67 & Variable & Variable & 0 & 52.5 \\
\hline
\end{tabular}

In addition to the linear elastic model, to perform non-linear analysis and to optimize nonlinear layer coefficients, the base and sub-base layers are defined as non-linear using the 
coefficients given in Table 2 [51]. To optimize the non-linear layer coefficients in accordance with the AASHTO-93 method, the $\mathrm{K}_{1}$ and $\mathrm{K}_{2}$ coefficients of the base and sub-base layers were determined as variables and analyses were made for 60 different $\mathrm{K}_{1}-\mathrm{K}_{2}$ combinations for the base layer and 360 combinations for the sub-base layer.

In Table $2, \mathrm{~K}_{0}$ is the soil pressure at rest and is proposed as 0.8 or calculated by Equation 8 according to the Poisson's ratio of the layer [1].

$K_{0}=v /(1-v)$

$\mathrm{K}_{1}$ is a non-linear coefficient which varies with the moisture content of the granular layers, and $\mathrm{K}_{2}$ is a non-linear exponent, the proposed $\mathrm{K}_{1}$ and $\mathrm{K}_{2}$ values for granular base layers are given in Tables 3 and 4, and the recommended $K_{1}$ and $K_{2}$ values for granular sub-base layers are given in Table 5. PHI is the internal friction angle of granular layers. The ZCNOL value is the depth of calculation of the modulus of elasticity for non-linear layers and is recommended to be taken as the mid-depth of the layer [1].

Table 3 - Recommended $K_{1}$ and $K_{2}$ values for base layers

\begin{tabular}{llcr}
\hline Reference & Material & $\mathrm{K}_{1}(\mathrm{kPa})$ & $\mathrm{K}_{2}$ \\
\hline Hicks (1970) & Partially crushed gravel, crushed rock & $11032-34474$ & $0.57-0.73$ \\
Hicks and Finn (1970) & Untreated base at San Diego test road & $14479-37232$ & 0.61 \\
Allen (1973) & Gravel, crushed stone & $12411-55159$ & $0.32-0.70$ \\
Kalcheff ve Hicks (1973) & Crushed stone & $27580-62053$ & $0.46-0.64$ \\
Boyce et al. (1976) & Well-graded crushed limestone & 55159 & 0.67 \\
Monismith and Witczak (1982) & In service base and sub-base materials & $19995-53435$ & $0.46-0.65$ \\
\hline
\end{tabular}

Table 4 - $K_{1}$ and $K_{2}$ values based on moisture content for base layers [1]

\begin{tabular}{lcc}
\hline Mositure content & $\mathrm{K}_{1}(\mathrm{kPa})$ & $\mathrm{K}_{2}$ \\
\hline Dry & $41369-68948$ & $0.5-0.7$ \\
Damp & $27580-41369$ & $0.5-0.7$ \\
Wet & $13790-27580$ & $0.5-0.7$ \\
\hline
\end{tabular}

Table 5 - $K_{1}$ and $K_{2}$ values based on moisture content for sub-base layers [1]

\begin{tabular}{lcc}
\hline Moisture content & $\mathrm{K}_{1}(\mathrm{kPa})$ & $\mathrm{K}_{2}$ \\
\hline Dry & $41369-55159$ & $0.4-0.6$ \\
Damp & $27580-41369$ & $0.4-0.6$ \\
Wet & $10343-27580$ & $0.4-0.6$ \\
\hline
\end{tabular}




\section{RESULTS AND DISCUSSION}

\subsection{Obtaining the Empirical Transfer Model Compatible with AASHTO-93 and Determining the Target Strain}

$\mathrm{T}_{8.2}$ values for different road types and reliability levels were calculated by the AASHTO-93 method and given in Table 6 depending on the subgrade resilient modulus, layer thickness, layer coefficients, and drainage coefficients given in Figure 1.

Table 6 - AASHTO-93 design results

\begin{tabular}{lcccc}
\hline Road type & $\mathrm{R}(\%)$ & $\mathrm{ZR}$ & $\mathrm{Pt}$ & $\mathrm{T}_{8.2}\left(\mathrm{x} 10^{6}\right)$ \\
\hline Highway & 95 & -1.645 & 2.5 & 23.35 \\
State road & 85 & -1.037 & 2.5 & 43.75 \\
Provincial road & 70 & -0.524 & 2.0 & 124.5 \\
\hline
\end{tabular}

As a result of the mechanical analysis of the section by defining the layers linear elastic, the horizontal strain value under the surface layer was obtained as $2.124 \times 10^{-4}$, and the vertical strain value on the subgrade was $2.345 \times 10^{-4}$. Based on these responses, the pavement life values calculated by empirical transfer equations are shown in Table 7.

Table 7 - M-E design results

\begin{tabular}{|c|c|c|c|c|c|c|c|c|}
\hline & 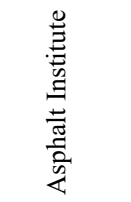 & 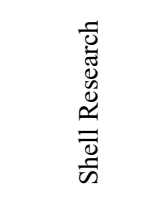 & 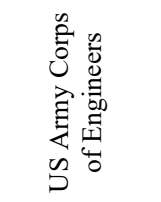 & 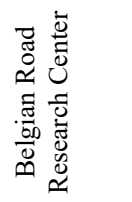 & 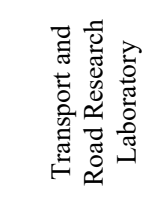 & 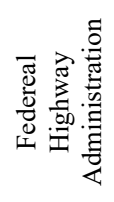 & 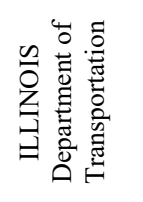 & 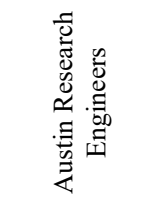 \\
\hline $\mathrm{Nf}$ & 1303655 & 1521195.97 & 765525.96 & 14952.36 & 1221238.80 & 4832.25 & 521802.87 & 12472426.51 \\
\hline $\mathrm{Nr}$ & 24322215 & 203377885 & 890750781.7 & 18800892 & 46242655.65 & -- & --- & --- \\
\hline
\end{tabular}

Table 7 shows that different transfer equations give quite different pavement life values. In particular, fatigue-related values are very low compared to pavement life due to rutting. When eight values related to fatigue and six values related to rutting are examined, it has been determined that the $\mathrm{Nr}$ equations of Asphalt Institute (AI) for highways and Transport and Road Research Laboratory for state roads are $96 \%$ and $94.6 \%$ compatible with the AASHTO-93 method respectively. For provincial roads with a low level of reliability, a highly compatible model could not be determined.

When the Highway Flexible Pavement Design Guide [5] is examined, the sum of the recommended bituminous layer thicknesses for all $\mathrm{R}$ and $\mathrm{T}_{8.2}$ values is $19 \mathrm{~cm}$ and above (except only $\mathrm{R}=70 \%$ and $\mathrm{T}_{8.2}=3-10 \times 10^{6}$ ). 
In the current study, the bituminous surface layer thickness was chosen as $15 \mathrm{~cm}$. Therefore, the main failure type for the section was determined as rutting since the surface layer was not thick enough according to the AASHTO-93 method, and therefore the load transmitted to the subgrade increased.

However, the most important point to be noted here is that when the cross-section type and thickness change, the prior failure can be changed, and the fatigue models of the M-E method can also be compatible with AASHTO-93.

Consequently, the rutting equation of $\mathrm{AI}$ was chosen as the transfer equation for the optimization of non-linear layer coefficients. In this equation, $\varepsilon_{\mathrm{v}}$ value provides the $\mathrm{T}_{8.2}$ of the AASHTO-93 method is obtained as the target strain $\left(2.366 \times 10^{-4}\right)$ (Equation 7$)$. In the following sections of the study, it is aimed to obtain non-linear layer coefficients which provide this target strain.

\subsection{Obtaining Non-Linear Layer Coefficients for Base and Sub-base Layers}

The $\mathrm{K}_{1}$ and $\mathrm{K}_{2}$ values used in the nonlinear elastic definition of the base and sub-base layers significantly affect the mechanical response values, and these values vary in a wide range according to the type, crush condition, moisture content and granulometry of the aggregate as shown in Table 3-5.

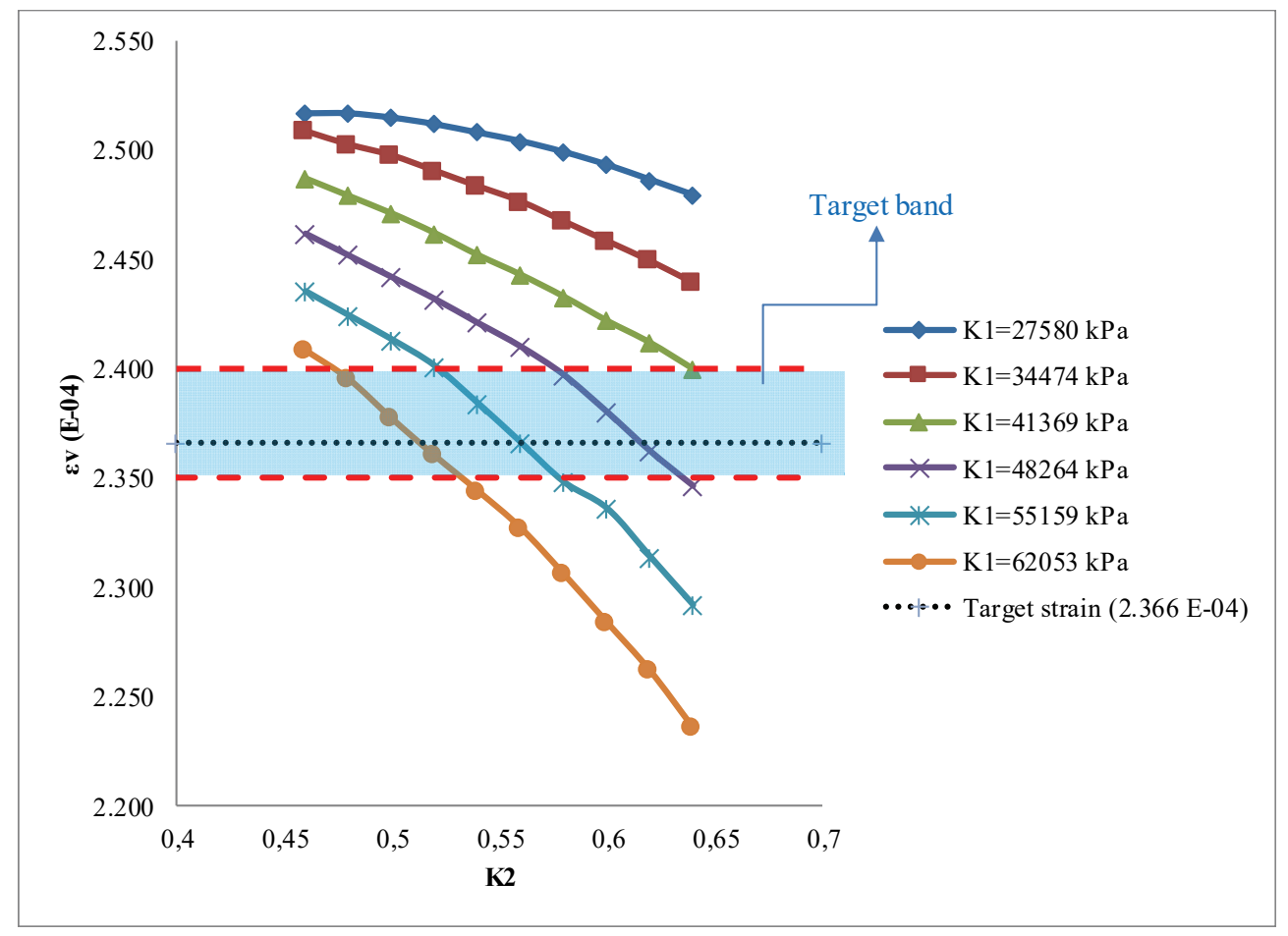

Figure 3 - Analysis results for base layer optimization 
If the $K_{1}$ and $K_{2}$ values can be optimized for base and sub-base layers, a cross-section designed according to AASHTO-93 can be re-analyzed with various loading, material, contact, and environmental conditions and pavement responses and the pavement life values can be determined with M-E design for any distress mode. To determine the non-linear layer coefficients of these two layers, firstly the base layer was defined as non-linear elastic, and the other layers as linear elastic, and $\mathrm{K}_{1}$ and $\mathrm{K}_{2}$ values providing the target strain were obtained. The wet moisture content condition is neglected, and $\mathrm{K}_{1}$ is determined between 27580 and $62053 \mathrm{kPa}, \mathrm{K}_{2}$ is selected between 0.46 and 0.64 compatible to the literature, so 60 different combinations of $\mathrm{K}_{1}$ and $\mathrm{K}_{2}$ were performed mechanically and the results are shown in Figure 3.

In the graph given in Figure 3, $K_{2}$ increases for any fixed $K_{1}$ value, and $K_{1}$ increases for any fixed $K_{2}$ value with decreasing $\varepsilon_{v}$ values. That is the deformation resistance of the crosssection increases. The values of $K_{1}$ and $K_{2}$ of the base layer are not selected only from combinations that provide target strain, instead, combinations from the $2.4 \times 10^{-4}-2.35 \times 10^{-4}$ band (Figure 3) were selected, and the effects of non-linear definition of the sub-base in the next step were also considered. The target strain line intersects with the curves $K_{1}=48264$, 55159 , and $62053 \mathrm{kPa}$. No matter how far the lower bound line of target band is positioned from the target strain, an intersection with a new $\mathrm{K}_{1}$ value cannot be achieved. For this reason, the lower limit of the target band was kept at $2.35 \mathrm{E}-04$. The upper limit of the target band was determined at $2.4 \mathrm{E}-04$ to intersect with the curve of $41369 \mathrm{kPa}$, which is the lower limit value of $\mathrm{K}_{1}$ for dry aggregate. Thus, the number of values to be worked on for optimization has been increased.

According to Figure 3 , the combinations of $\mathrm{K}_{1}$ and $\mathrm{K}_{2}$ in the targeted strain band are shown in Table 8.

Table $8-K_{1}$ and $K_{2}$ values that provide the target strain for the base layer

\begin{tabular}{lccccccccc}
\hline $\mathrm{K}_{1}(\mathrm{kPa})$ & 62053 & 62053 & 55159 & 55159 & 55159 & 48264 & 48264 & 48264 & 41369 \\
$\mathrm{~K}_{2}$ & 0.48 & 0.52 & 0.52 & 0.54 & 0.56 & 0.58 & 0.60 & 0.62 & 0.64 \\
$\varepsilon_{\mathrm{v}}\left(\mathrm{x} 10^{-4}\right)$ & 2.395 & 2.36 & 2.4 & 2.384 & 2.366 & 2.397 & 2.380 & 2.362 & 2.4 \\
\hline
\end{tabular}

With the aim of obtaining the non-linear layer coefficients of the sub-base layer, mechanical analyses with various sub-base parameters were performed for each base combination shown in Table 8, and $\mathrm{K}_{1}$ and $\mathrm{K}_{2}$ values were obtained for the target strain. 360 analyses were performed by selecting $\mathrm{K}_{1}$ values between 27580 and $55159 \mathrm{kPa}$ and $\mathrm{K}_{2}$ values between 0.4 and 0.6 , and the results are given in Figures 4-12.

When the figures giving the results of the sub-base mechanical analysis are viewed, the $\varepsilon_{\mathrm{v}}$ values decrease while increasing $\mathrm{K}_{2}$ at relatively high $\mathrm{K}_{1}$ values (48264-55159 $\mathrm{kPa}$ ), and the $\varepsilon_{\mathrm{v}}$ values increase as $\mathrm{K}_{2}$ increases in combinations where $\mathrm{K}_{1}$ has relatively lower values (27580-34474kPa). According to these results, $\mathrm{K}_{2}$ value shows a reversible behavior in a weak sub-base layer under a high-strength base layer. 
Optimizing Non-linear Granular Layer Coefficients of a Flexible Pavement for ...

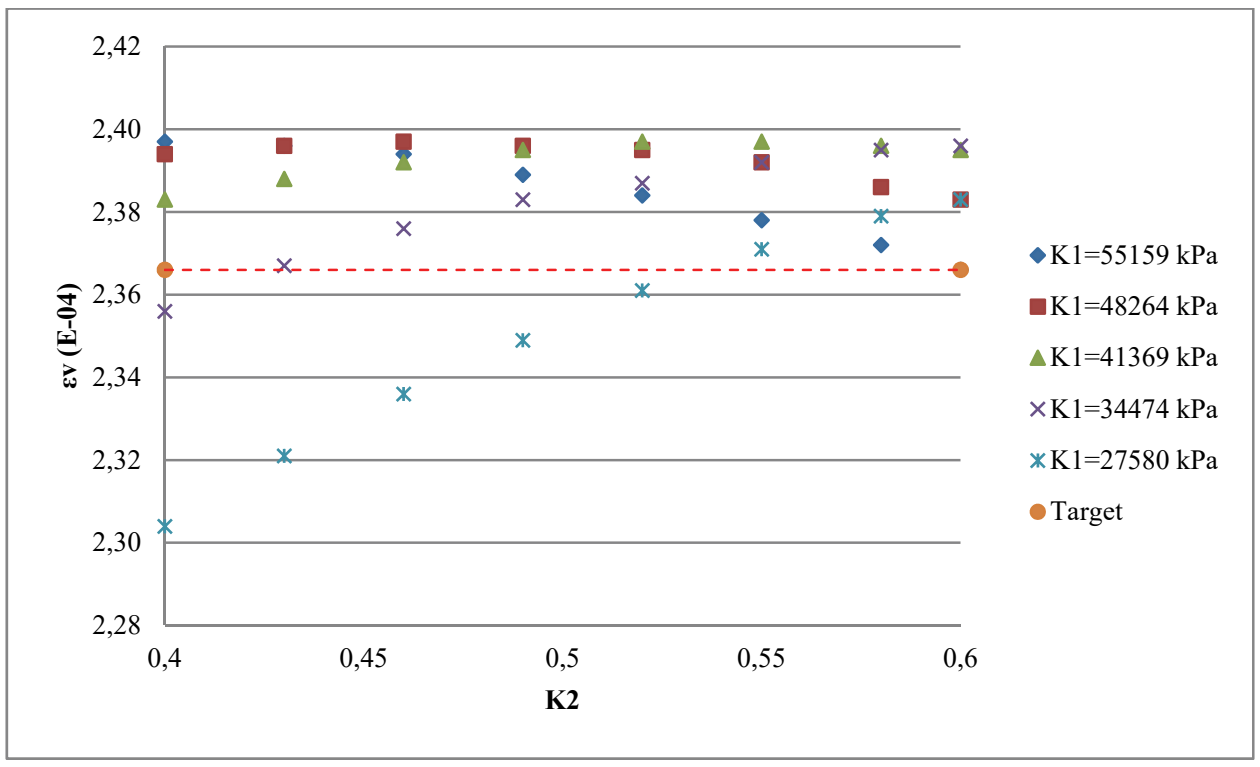

Figure 4 - Analysis results for sub-base layer (Base layer $K_{l}=62053 \mathrm{kPa}, K_{2}=0.48$ )

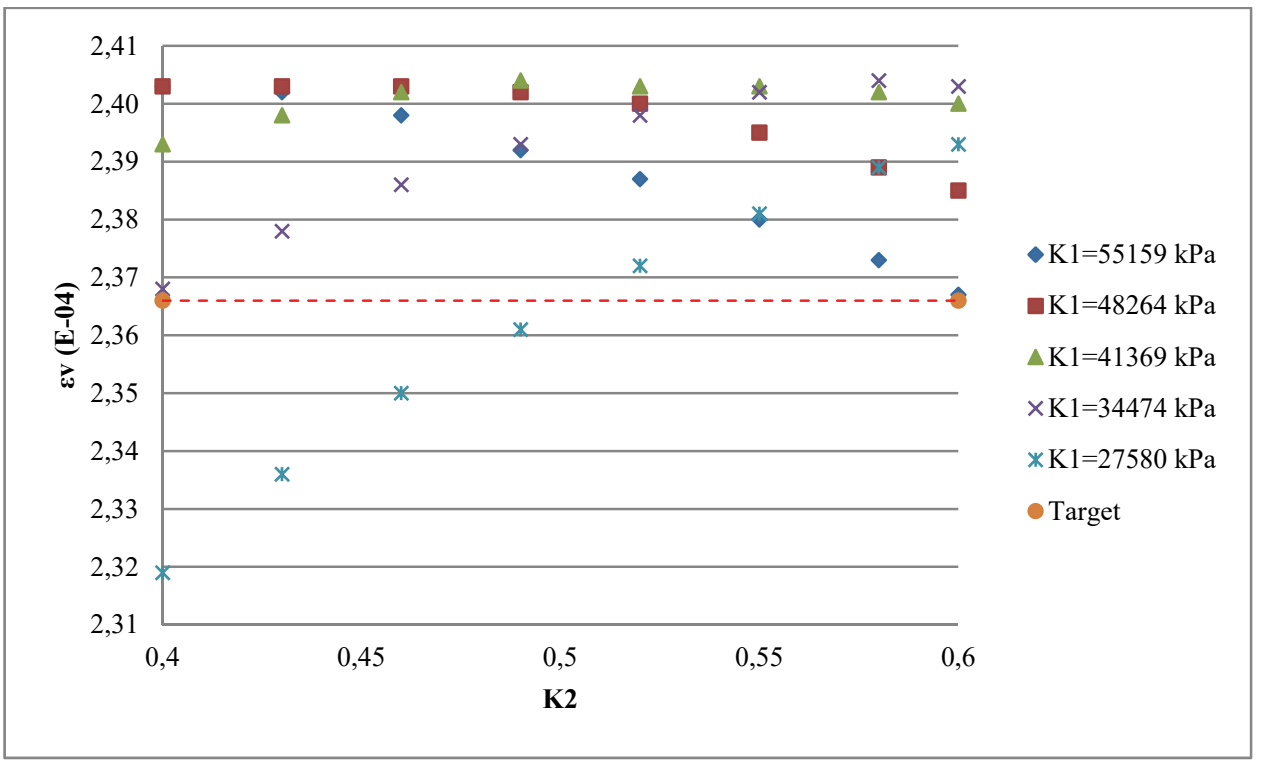

Figure 5 - Analysis results for sub-base layer (Base layer $K_{1}=62053 \mathrm{kPa}, K_{2}=0.52$ ) 


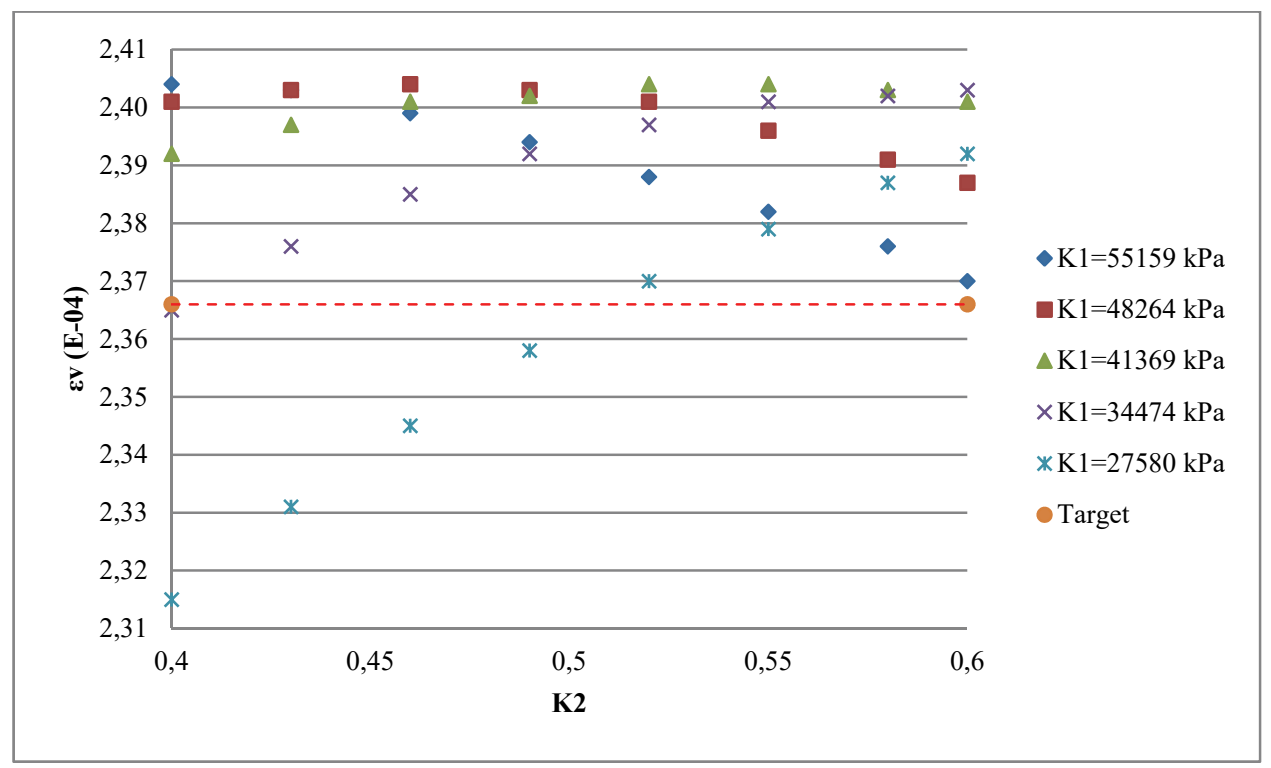

Figure 6 - Analysis results for sub-base layer (Base layer $K_{1}=55159 \mathrm{kPa}, K_{2}=0.52$ )

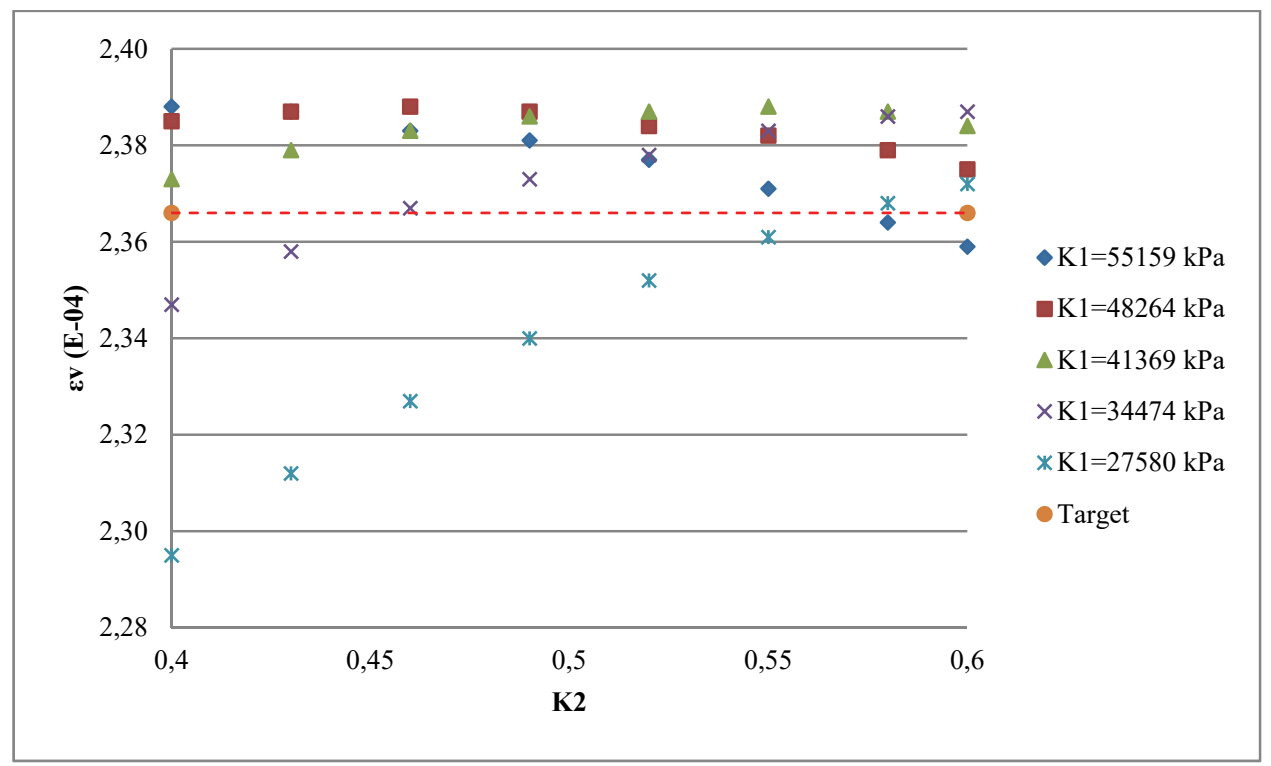

Figure 7 - Analysis results for sub-base layer (Base layer $K_{l}=55159 \mathrm{kPa}, K_{2}=0.54$ ) 
Optimizing Non-linear Granular Layer Coefficients of a Flexible Pavement for ...

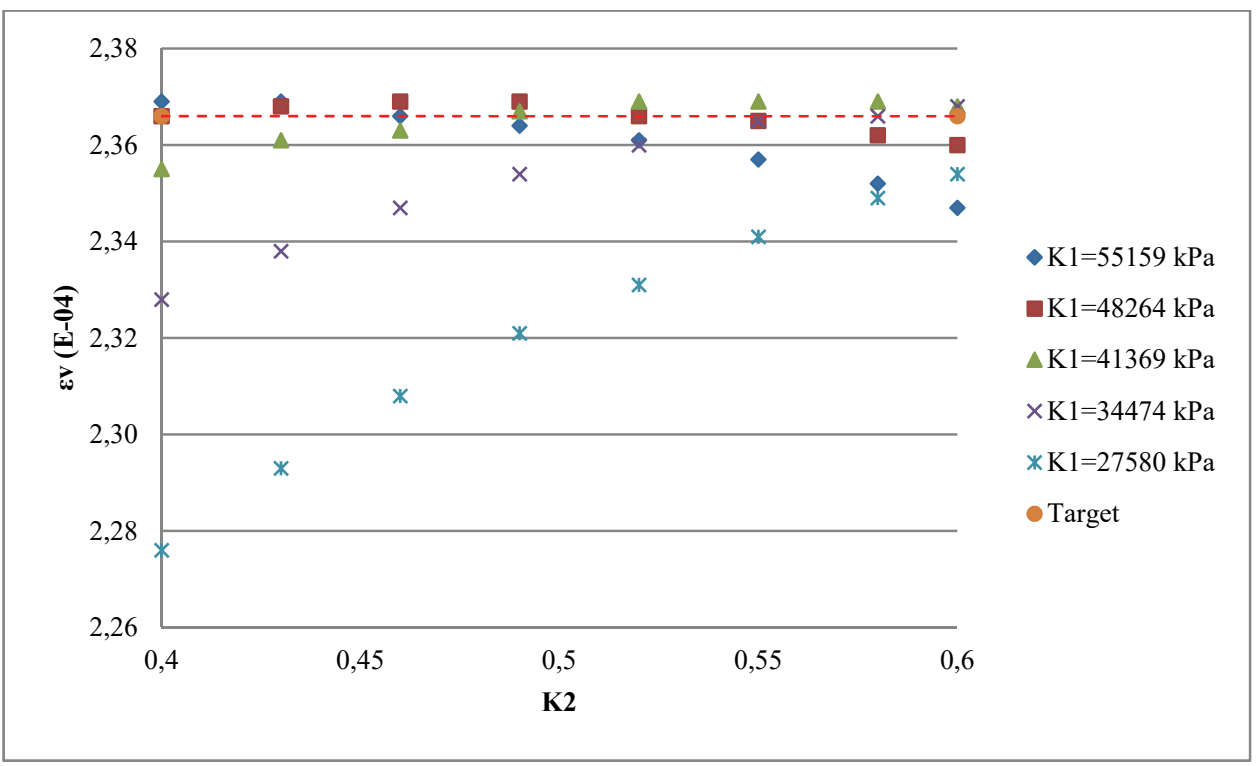

Figure 8 - Analysis results for sub-base layer (Base layer $K_{l}=55159 \mathrm{kPa}, \mathrm{K}_{2}=0.56$ )

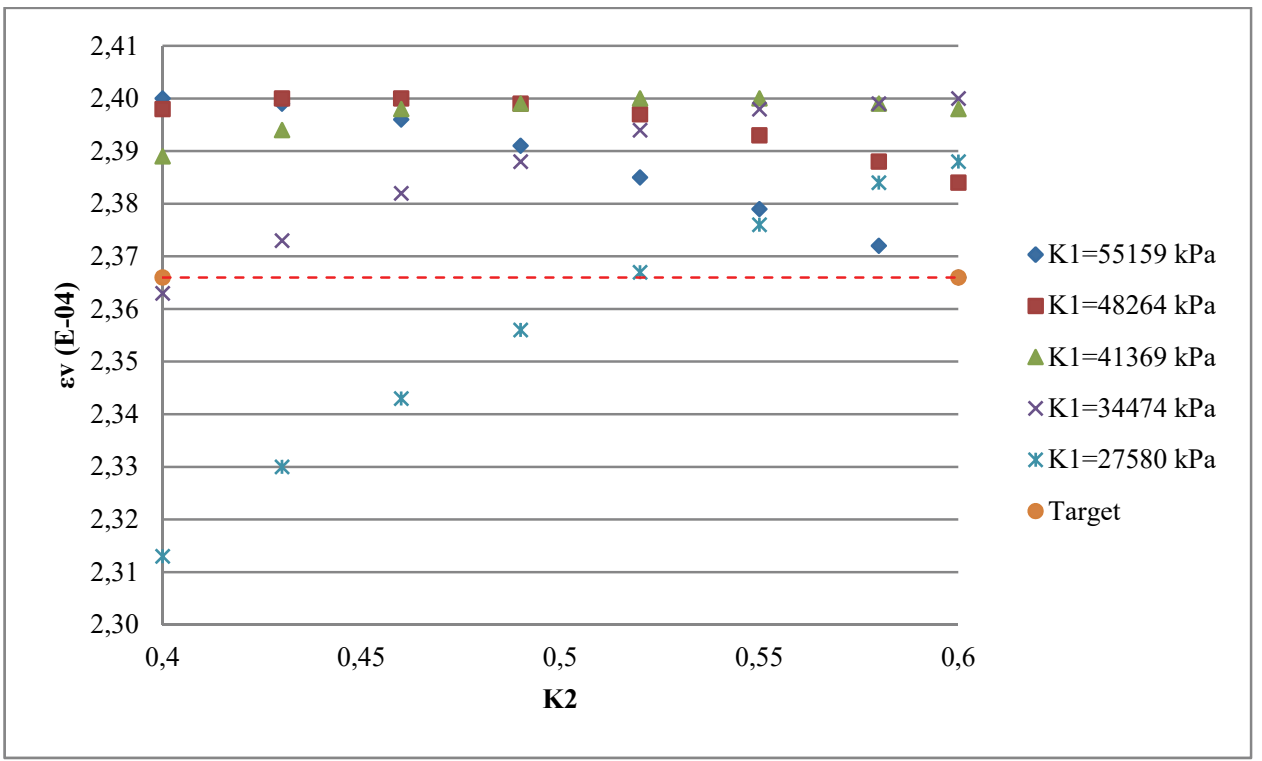

Figure 9 - Analysis results for sub-base layer (Base layer $K_{1}=48264 \mathrm{kPa}, K_{2}=0.58$ ) 


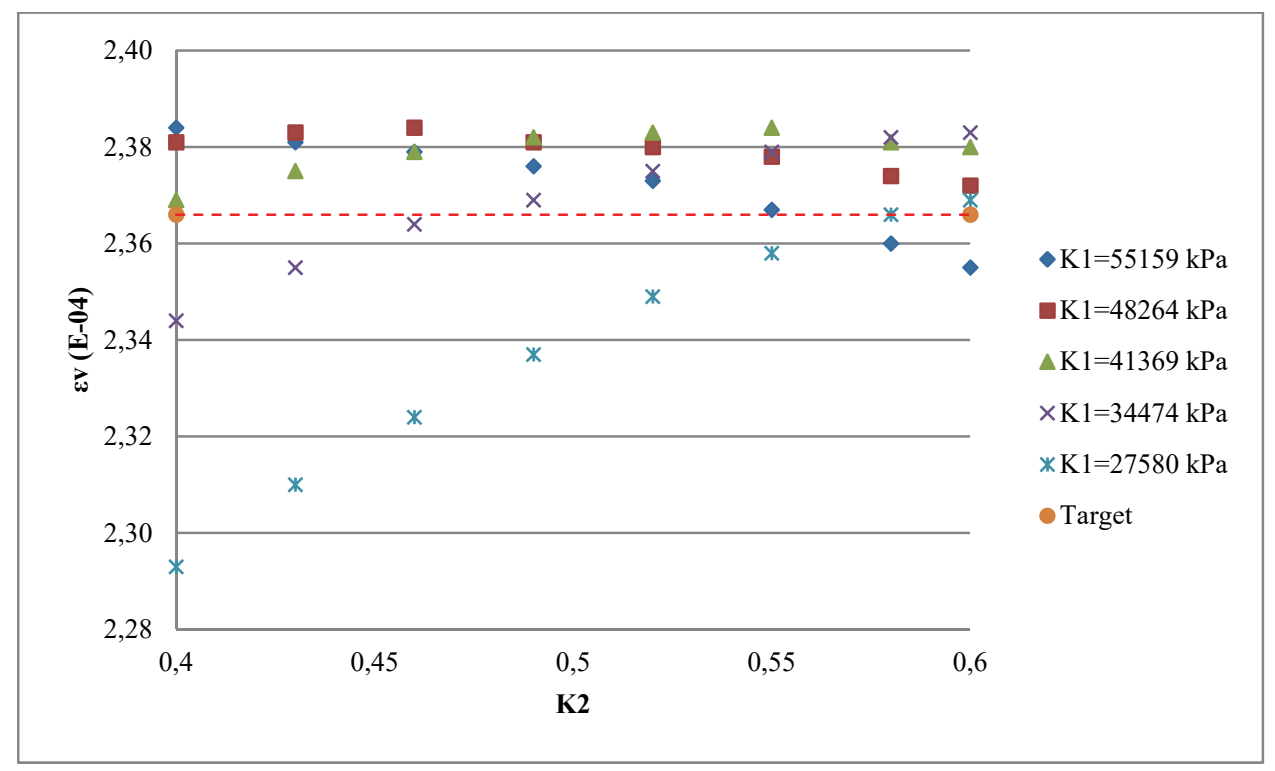

Figure 10 - Analysis results for sub-base layer (Base layer $K_{1}=48264 \mathrm{kPa}, K_{2}=0.60$ )

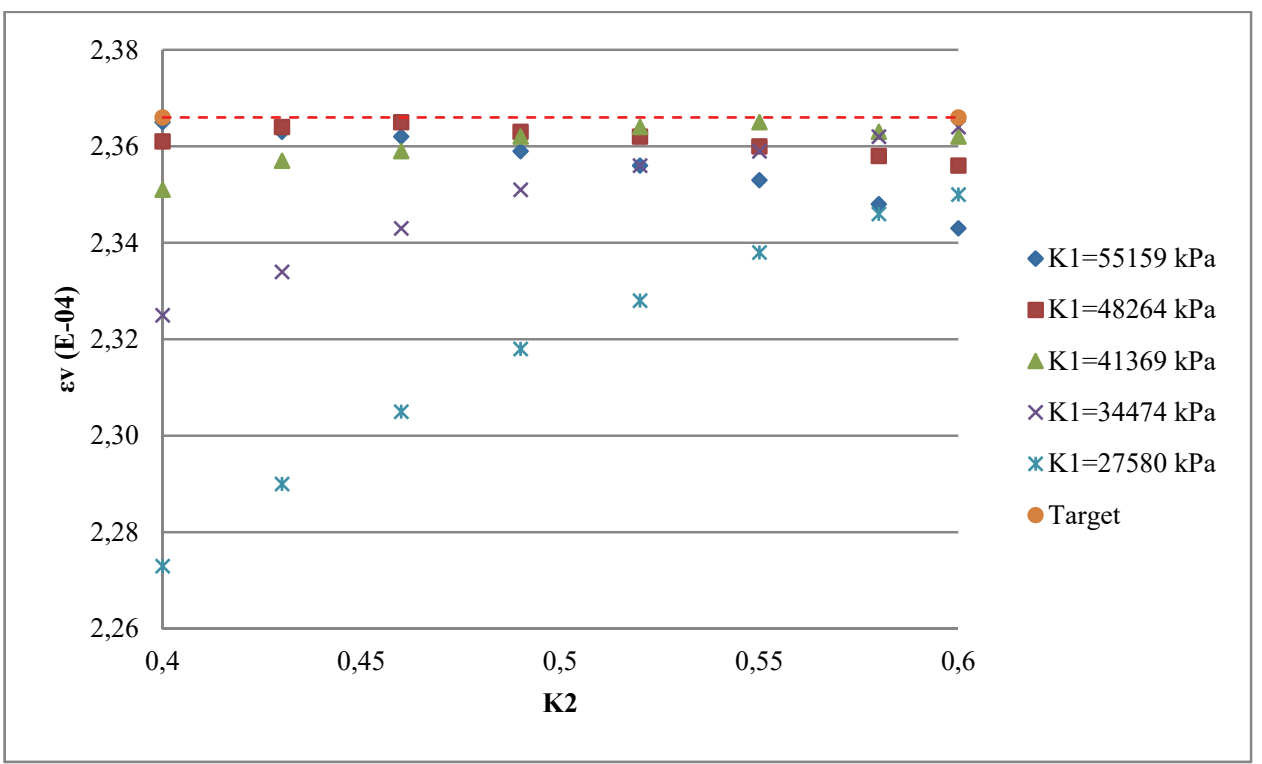

Figure 11 - Analysis results for sub-base layer (Base layer $K_{1}=48264 \mathrm{kPa}, K_{2}=0.62$ ) 


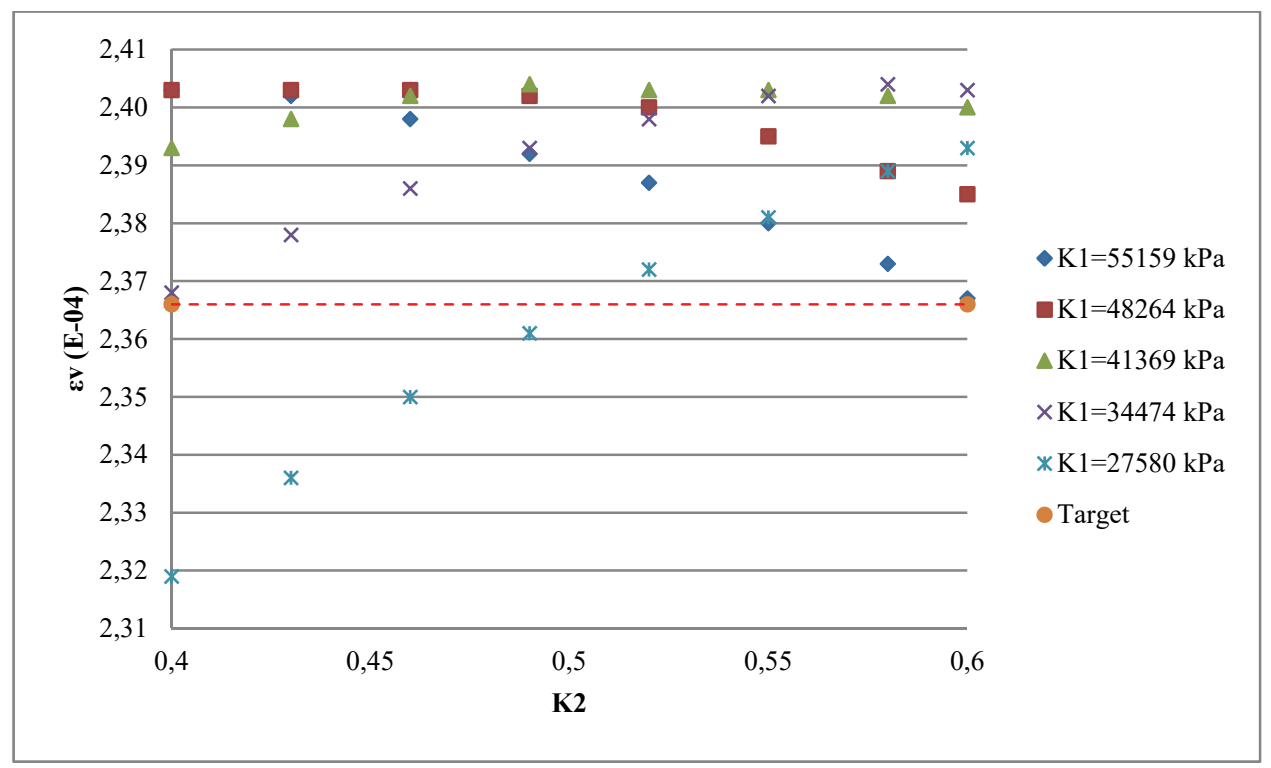

Figure 12 - Analysis results for sub-base layer (Base layer $K_{1}=41369 \mathrm{kPa}, K_{2}=0.64$ )

In Figures 4-12, the target strain values are shown with dashed lines, and the sub-base $\mathrm{K}_{1}$ and $\mathrm{K}_{2}$ combinations that intersect with these lines are determined. Accordingly, the combinations obtained as a result of defining both base and sub-base layers as non-linear elastic are shown in Table 9.

Table 9 - Optimum base and sub-base coefficient combinations

\begin{tabular}{cccccc}
\hline & \multicolumn{2}{c}{ Base layer } & \multicolumn{4}{c}{ Sub-base layer } \\
Combination number & $\mathrm{K}_{1}(\mathrm{kPa})$ & $\mathrm{K}_{2}$ & $\mathrm{~K}_{1}(\mathrm{kPa})$ & $\mathrm{K}_{2}$ & $\varepsilon_{\mathrm{v}}\left(\mathrm{x} 10^{-4}\right)$ \\
\hline 1 & 55159 & 0.56 & 55159 & 0.46 & 2.366 \\
2 & 55159 & 0.56 & 48264 & 0.40 & 2.366 \\
3 & 55159 & 0.56 & 48264 & 0.52 & 2.366 \\
4 & 55159 & 0.56 & 34474 & 0.58 & 2.366 \\
5 & 62053 & 0.48 & 55159 & 0.60 & 2.366 \\
6 & 48264 & 0.58 & 55159 & 0.60 & 2.366 \\
7 & 48264 & 0.60 & 27580 & 0.58 & 2.366 \\
\hline
\end{tabular}

When Table 9 is examined, it is seen that the optimum $\mathrm{K}_{1}$ values obtained for the base layer are higher than the other tested values and provide high deformation resistance. In the 1,2, 3 and 4 numbered combinations, the $\mathrm{K}_{1}$ and $\mathrm{K}_{2}$ values of the base layer remained the same, while the $\mathrm{K}_{1}$ and $\mathrm{K}_{2}$ values of the sub-base layer varied. In particular, when the combinations 2 and 3 were examined, the $K_{1}$ values of the sub-base layer under the same base were fixed 
as $48264 \mathrm{kPa}$ while the $\mathrm{K}_{2}$ value increased from 0.40 to 0.52 , and this change did not affect the strain values. Accordingly, the importance of the $\mathrm{K}_{2}$ value of sub-base in pavements consisting of a rigid base and a rigid sub-base can be relatively smaller. Also, when all the base and sub-base combinations in Table 9 are evaluated together, it can be stated that the $\mathrm{K}_{1}$ and $\mathrm{K}_{2}$ values used for the M-E design to give similar results with the AASHTO-93 method reflect the dry, crushed and well-graded granular material properties.

According to the Turkish Highway Technical Specifications [52], gravel, crushed gravel, terrace gravel, crushed stone, and crushed slag as a base material, sand, gravel, terrace gravel, decomposed rock, slag, and crushed stone can be used as a sub-base material. When the values obtained in Table 9 are evaluated according to the material properties used in base and sub-base layers, the optimum values obtained for the base layer generally reflect dry and well-graded crushed stone aggregate properties (Table 3). Accordingly, the designer may find that the AASHTO-93 and M-E design methods will yield consistent results for a base layer to be constructed with well-graded and dry crushed stone aggregate. However, when the material type and moisture content used in the base layer change, the M-E design method must be included in the design as well as the AASHTO-93 method. For different $\mathrm{K}_{1}$ and $\mathrm{K}_{2}$ values selected from Tables 3 and 4 following the material type and moisture content to be used in construction, the results to be obtained will be different from the results of AASHTO93.

When the optimum values obtained for the sub-base layer are compared with the $K_{1}$ and $K_{2}$ values depending on the moisture content given in Table 5, it can be seen that the dry subbase material is generally compatible with the AASHTO-93 method. However, when using damp sub-base material (combination number 4 and 7), a compatible base layer must be defined.

\section{CONCLUSIONS}

According to the results obtained from the study, in which the AASHTO-93 method is compared with different empirical transfer models in the M-E design method in terms of pavement life, and the non-linear elastic layer parameters used in mechanical analysis are optimized, the following inferences can be made.

- Axle loads and configurations, tire pressures and patterns, mechanical properties of pavement layers, and climate and environmental conditions are constantly changing. For this reason, in the design of flexible pavements, the M-E design method must be taken into consideration together with empirical methods developed according to certain experimental parameters.

- The empirical pavement life estimation models used in the M-E design proposed by different organizations give quite different results from each other and the AASHTO-93 method. While the mean value obtained from the $\mathrm{N}_{\mathrm{f}}$ estimation models is calculated as $2.228 \times 10^{6}$, its standard deviation is $3.908 \times 10^{6}$, and the coefficient of variation is $175 \%$, for rutting models the mean is $236.7 \times 10^{6}$, the standard deviation is $333.99 \times 10^{6}$, and the coefficient of variation is $141 \%$. This high statistical values, especially in the coefficients of variation, show that calibration of the pavement life estimation model in M-E design methods is critical. 
- In the flexible pavement design, the main type of deterioration the road will be exposed to should be prioritizedbecause different distress models of the same agency, show highly different design results. When $\mathrm{Nr} / \mathrm{Nf}$ values are calculated for AI, Shell, US Army Corps of Engineers, Belgian Road Research Center, and Transport and Road Research Laboratory models, the results are obtained as 18.66, 133.7, 1163.6, 1257.4 and 37.9, respectively. When these results are taken into consideration, it is of great importance to estimate the prior distress type of pavement. Considering that the AASHTO-93 method, which is compared with the M-E methods in the present study, yields more consistent results with the transfer equations related to the rutting, the reliability of the AASHTO design decreases significantly for a cross-section subject to fatigue under heavy traffic.

- The cross-section analyzed in this study gave more consistent results with the rutting models in terms of layer thickness (especially $15 \mathrm{~cm}$ surface layer). However, if the cross-section type changes and thicker surface layers are used in the surface layer, the prior distress type may return to fatigue. In this case, while the unbound layer coefficients are optimized, tensile strain under the surface layer should be used as the target strain.

- In this study, the optimum layer coefficients obtained for the base and sub-base layers show that the materials used in the layers are constructed with well-graded and dry aggregates. In this case, the AASHTO-93 and M-E methods are compatible with each other. However, as the materials used in the base and sub-base layers and moisture contents change, M-E methods must be included in the design solution that takes into account the non-linear behavior of the materials.

- In the empirical pavement design methods related to the road tests, the change of the parameters used in the test affects the design results. It is a remarkable subject of study that the empirical method results are associated with an M-E method since it is not possible to examine a large number of parameters that affect the design of pavement. Thus, M-E design parameters (layer material characterization, contact type, etc.) can be optimized according to the empirical method outputs, and various analyses can be made with M-E design with different loading and environmental conditions.

\section{Funding}

This work is supported by the Scientific Research Project Fund of Sivas Cumhuriyet University under the project number M-753.

\section{References}

[1] Huang, Y. H., Pavement analysis and design. 2nd ed. Upper Saddle River, NJ: Pearson Prentice Hall, 1993.

[2] Mashayekhi, M., Amini, A.A., Behbahani, H., Nobakht, S., Comparison of mechanistic-empirical and empirical flexible pavement design procedures of AASHTO: A Case Study, 5th International Conference Bituminous Mixtures and Pavements, Thessaloniki, 2011. 
[3] Alhasan, A., Ali, A., Offenbacker, D., Smadi, O., Lewis-Beck, C., Incorporating spatial variability of pavement foundation layers stiffness in reliability-based mechanisticempirical pavement performance prediction, Transportation Geotechnics, 17, 1-13, 2018.

[4] Carvalho, R. L., Schwartz, C. W., Comparisons of flexible pavement designs: AASHTO empirical versus NCHRP project 1-37A mechanisticempirical, Transportation Research Record, 1947(1), 167-174, 2006.

[5] Sağlık, A., Güngör, A.G., Highways flexible pavement design guide, Ankara, 2008.

[6] Çelik, O. N., Eyada, S. O., Assessment of flexible pavement fatigue life of Turkish typical sections using mechanistic empirical pavement design approach for coastal region, Ain Shams Engineering Journal, 10(1), 33-43, 2019.

[7] Muniandy, R., Aburkaba, E., Thamer, N., Comparison of flexible pavement performance using Kenlayer and Chev PC software program, Australian Journal of Basic and Applied Sciences, 7(9), 112-119, 2013.

[8] Behiry, A. E. A. E. M., Fatigue and rutting lives in flexible pavement, Ain Shams Engineering Journal, 3(4), 367-374, 2012.

[9] Mousa, M. R., Abo-Hashema, M.A., Gadallah, A.A., Mousa, R.M., Evaluation of pavement performance prediction models under different traffic and climatic conditions, The Proceedings of International Conference on Asphalt Pavement Engineering and Infrastructure, London, 2015.

[10] Singh, A. K., Sahoo, J. P., Analysis and design of two layered flexible pavement systems: A new mechanistic approach, Computers and Geotechnics, 117, 103238, 2020.

[11] Abd Alla, E. M., The rational use of finite element method in the analysis of flexible pavements, Journal of Engineering Sciences, Assiut University, 34(4), 1185-1211, 2006.

[12] Titi, H. H., Matar, M. G., Estimating resilient modulus of base aggregates for mechanistic-empirical pavement design and performance evaluation, Transportation Geotechnics, 17, 141-153, 2018.

[13] Ng, K., Henrichs, Z.R., Ksaibati, K., Wulff, S.S., Resilient modulus of subgrade materials for mechanistic-empirical pavement design guide, Road Materials and Pavement Design, 19(7), 1523-1545, 2018.

[14] Shahji, S. Sensitivity analysis of AASHTO'S 2002 flexible and rigid pavement design methods, Thesis (MSc), University of Central Florida, 2006.

[15] Masad, S.A., Little, D.N., Sensitivity analysis of flexible pavement response and AASHTO 2002 design guide to properties of unbound layers. Research report ICAR 504-1, International Center for Aggregates Research, 2004.

[16] Cerni, G., Cardone, F., Virgili, A., Camilli, S., Characterisation of permanent deformation behaviour of unbound granular materials under repeated triaxial loading, Construction and Building Materials, 28(1), 79-87, 2012. 
[17] Sahin, H., Gu, F., Tong, Y., Luo, R., Lytton, R. L., Unsaturated soil mechanics in the design and performance of pavements, Advances in Unsaturated Soils, 105-118, 2013.

[18] Ahirwar, S. K., Mandal, J. N., Finite element analysis of flexible pavement with geogrids, Procedia Engineering, 189, 411-416, 2017.

[19] Seed, H. B., Mitry, F.G., Monismith, C.L., Chan, C.K., Prediction of flexible pavement deflections from laboratory repeated-load tests, Report No: 35, NCHRP, 1967.

[20] May, R. W., Witczak, M. W., Effective granular modulus to model pavement responses, Transportation Research Record, 810, 1-9, 1981.

[21] Uzan, J., Characterization of granular material, Transportation Research Record, 1022(1), 52-59, 1985.

[22] Ni, B., Hopkins, T.C., Sun, L., Beckham, T.L., Modeling the resilient modulus of soils, Proceedings of the 6th International Conference on the Bearing Capacity of Roads and Airfields, Lisbon, 2002.

[23] Luo, X., Gu, F., Zhang, Y., Lytton, R. L., Zollinger, D., Mechanistic-empirical models for better consideration of subgrade and unbound layers influence on pavement performance, Transportation Geotechnics, 13, 52-68, 2017.

[24] Masad, S., Little, D., Masad, E., Analysis of flexible pavement response and performance using isotropic and anisotropic material properties, Journal of Transportation Engineering, 132(4), 342-349, 2006.

[25] Adu-Osei, A., Little, D. N., Lytton, R. L., Cross-anisotropic characterization of unbound granular materials, Transportation Research Record, 1757(1), 82-91, 2001.

[26] Tutumluer, E., Thompson, M. R., Anisotropic modeling of granular bases in flexible pavements, Transportation Research Record, 1577(1), 18-26, 1997.

[27] Yang, S. R., Huang, W. H., Tai, Y. T. Variation of resilient modulus with soil suction for compacted subgrade soils, Transportation Research Record, 1913(1), 99-106, 2005.

[28] Butalia, T.S., Huang, J., Kim, D.G., Croft, F., Effect of moisture content and pore water pressure buildup on resilient modulus of cohesive soils in Ohio, ASTM Special Technical Publication, 1437, 70-84, 2003.

[29] Wolfe, W., Butalia, T., Continued monitoring of SHRP pavement instrumentation including soil suction and relationship with resilient modulus, Report No: FHWA/OH2004/007, Department of Transportation, Federal Highway Administration, 2004.

[30] Gupta, S., Ranaivoson, A., Edil, T., Benson, C., Sawangsuriya, A., Pavement design using unsaturated soil technology, Report No: MN/RC-2007-11, University of Minnesota, 2007.

[31] Cary, C. E., Zapata, C. E., Resilient modulus for unsaturated unbound materials. Road Materials and Pavement Design, 12(3), 615-638, 2011.

[32] Ghadimi, B., Nikraz, H., A comparison of implementation of linear and nonlinear constitutive models in numerical analysis of layered flexible pavement, Road Materials and Pavement Design, 18(3), 550-572, 2017. 
[33] Ghanizadeh, A. R., Ziaie, A., NonPAS: a program for nonlinear analysis of flexible pavements, International Journal of Integrated Engineering, 7(1), 2015.

[34] Karagöz, C., Analysis of Flexible pavements incorporating nonlinear resilient behavior of unbound granular layers, Thesis (PhD), Middle East Technical University, 2004.

[35] Hicks, R. G., Factors influencing the resilient properties of granular materials, Thesis (PhD), University of California, Berkeley, 1970.

[36] Hicks, R. G., Finn, F. N., Analysis of results from the dynamic measurements program on the San Diego test road, Proceedings, Association of Asphalt Paving Technologists, 39, 153-185, 1970.

[37] Allen, J. J., The effects of non-constant lateral pressure on the resilient response of granular materials, Thesis (PhD), University of Illinois at Urbana-Champaign, 1973.

[38] Kalcheff, I. V., Hicks, R. G., A test procedure for determining the resilient properties of granular materials, Journal of Testing and Evaluation, 1(6), 472-479, 1973.

[39] Boyce, J. R., Brown, S. F., Pell, P. S., The resilient behaviour of a granular material under repeated loading, Australian Road Research Board Conference Proceedings, 8, $1-12,1976$.

[40] Monismith, C. L., Witczak, M. W., Moderator's report, paper in session I, Pavement Design, Proceedings Fifth International Conference on the Structural Design of Asphalt Pavements, Netherlands, 2, 2-58, 1982.

[41] Pan, E., Chen, E., Alkasawneh, W., An exploratory study on functionally graded materials with applications to multilayered pavement design, Report No: FHWA/OH2007/12, Department of Civil Engineering the University of Akron, 2007.

[42] Hafeez, I., Shan, A., Ali, A., Ahmed, I., Flexible pavement design evaluation using mechanistic-empirical approaches. Technical Journal, University of Engineering and Technology, 22, 27-33, 2017.

[43] Beskou, N. D., Tsinopoulos, S. V., Theodorakopoulos, D. D., Dynamic elastic analysis of 3-D flexible pavements under moving vehicles: A unified FEM treatment, Soil Dynamics and Earthquake Engineering, 82, 63-72, 2016.

[44] Al-Azzawi, A. A., Finite Element Analysis of Flexible Pavements Strengthed with Geogrid, ARPN Journal of Engineering and Applied Sciences, 7(10), 1295-1299, 2012.

[45] Ekwulo, E. O., Eme, D. B., Fatigue and rutting strain analysis of flexible pavements designed using CBR methods, African Journal of Environmental Science and Technology, 3(12), 2009.

[46] Perraton, D., Di Benedetto, H., Carter, A., Proteau, M., Link between different bottomup fatigue's law coefficients of mechanical-empirical pavement design software, Construction and Building Materials, 216, 552-563, 2019.

[47] Priest, A., Calibration of fatigue transfer functions for mechanistic-empirical flexible pavement design, Thesis (PhD), Auburn University, 2005. 
[48] Ziari, H., Khabiri, M. M., Interface condition influence on prediction of flexible pavement life, Journal of Civil Engineering and Management, 13(1), 71-76, 2007.

[49] Chegenizadeh, A., Keramatikerman, M., Nikraz, H., Flexible pavement modelling using Kenlayer, The Electronic Journal of Geotechnical Engineering, 21, 2467-2479, 2016.

[50] Hadi, M. N., Bodhinayake, B. C., Non-linear finite element analysis of flexible pavements, Advances in Engineering Software, 34(11-12), 657-662, 2003.

[51] Samad, E., Sensitivity analysis in flexible pavement performance using mechanistic empirical method (Case study: Cirebon-Losari road segment, West Java), Journal of the Civil Engineering Forum, 20(1), 1163-1174, 2011.

[52] Turkey General Directorate of Highways, Highways technical specification, Ankara, Turkey, 2013. 